\title{
INHIBITION OF OVULATION WITH SEQUENCE HORMONE THERAPY
}

\author{
S. ROZIN, M. SALZBERGER, S. DICKSTEIN AND M. SACKS \\ Departments of Obstetrics, Gynaecology, Pharmacology and Pathology, \\ Hadassah-University Hospital, \\ and Hebrew University-Hadassah Medical School, Jerusalem, Israel
}

(Received 22nd February 1966)

\begin{abstract}
Summary. Inhibition of ovulation was achieved by sequential administration of ethynyl oestradiol 3-methyl ether followed by 17-acetoxyprogesterone. One hundred and forty-three women received treatment for a total of 1274 cycles. No pregnancies occurred in the whole group during the period of drug administration and side-effects were minimal. In cases in which the endometrium was examined shortly before withdrawal bleeding occurred, the usual histological picture was that of an early secretory endometrium.
\end{abstract}

\section{INTRODUCTION}

Orally active inhibitors of ovulation are at present widely used for the control of conception. At first, synthetic gestagens were used to inhibit ovulation and it was subsequently found that the supplementation of 19-norsteroid therapy with oestrogens resulted in the establishment of regular menstruation (Rock, Pincus \& Garcia, 1956; Pincus, Rock \& Garcia, 1958).

Since 1961 we have been using a method of inhibition of ovulation consisting of the sequential administration of orally synthetic oestrogens and progestins. During our study other reports on sequential oestrogen and progestin control of ovulation have appeared (Goldzieher, Martinez-Manautou, Livingston, Moses \& Rice Wray, 1963; Goldzieher, Becerra, Guel, Livingston, Maqueo, Moses \& Tietze, 1964). The compounds used by us were ethynyl oestradiol 3-methyl ether (mestranol) and 17-acetoxy-progesterone.

\section{MATERIALS AND METHODS}

One hundred and forty-three women were under treatment for a total of 1274 cycles. Most of them had been proved to be fertile. In some women premenstrual endometrial biopsies had been performed, but in most of them the presence of ovulation was established by basal body temperature (BBT) recording and the cervical mucus crystallization. The latter test was performed in the mid-cycle and pre-menstrual periods. Many of the women had had recent pregnancies.

The great majority ranged from 19 to 34 years in age, and the remaining few were 35 to 38 years old. Women with palpable uterine myomata and obviously obese women were excluded from this study. 
The medication consisted of tablets containing $0.1 \mathrm{mg}$ of mestranol and capsules containing $100 \mathrm{mg}$ of 17 -acetoxy progesterone.

Treatment was started on the 5th day of the menstrual cycle. One tablet of mestranol was given daily for 16 days. This was followed by one capsule of 17 -acetoxy progesterone for the next 4 or 5 days (i.e. on the 21 st to 24 th or 25 th day of the cycle).

The patients were observed monthly during the first 3 months of treatment. During this period the patient had recorded the BBT and cervical mucus crystallization tests were performed. In a few cases endometrial biopsies were performed 1 to 3 days after taking the last capsule. After the first 3 months of treatment the patient was instructed to stop recording the BBT, but was seen at 3 -month intervals when she was examined and given a further supply of the drugs.

In most cases a treatment-free interval of one menstrual cycle was instituted after 6 to 12 months of treatment.

\section{RESULTS}

No pregnancies occurred during the period of treatment.

Six patients discontinued the treatment after 1 month, two of them because of nausea, three because of slight spotting between the 19th to 21st days of the cycle and one because of the inconvenience of taking tablets daily.

Three patients discontinued treatment after 2 months; two because of nausea and one because of breakthrough bleeding on the 19th day of the cycle.

Four patients discontinued treatment after 3 months-because of the inconvenience of taking the tablets and because they preferred the mechanical contraceptive devices used previously. No patients discontinued the treatment after 3 months, unless they wished to become pregnant.

There were twenty-four episodes of breakthrough bleeding in the whole series. This took the form of slight spotting or a slight bloody discharge which usually only lasted for 2 days but sometimes continued until menstruation ensued. No change in medication was instituted because of the occurrence of such breakthrough bleeding.

Nausea was reported by sixteen patients, in twelve of whom it was a troublesome symptom for the first and second cycles but subsided thereafter. In only four cases was nausea the reason for discontinuing the tablets. To avoid nausea the patients were instructed to take the pills with milk before retiring.

Menstruation usually resembled a normal menstrual flow in its occurrence and duration. However, changes in the amount and duration of the menstrual flow were occasionally observed. In two women, in whom the smaller doses of the progesterone compound ( $50 \mathrm{mg}$ ) were given, amenorrhoea was observed.

During the 5 th to 22 nd days the basal body temperature remained constantly low but rose on the day after the progestative drug was started.

Excessive weight gain occurred in six of the patients.

Endometrial biopsies were performed 1 to 2 days after cessation of therapy in six patients. In four patients, the endometrial glands showed early secretory activity in the form of well-marked subnuclear vacuolation and the stroma was mildly oedematous (Plate 1). In one case the endometrium showed more 

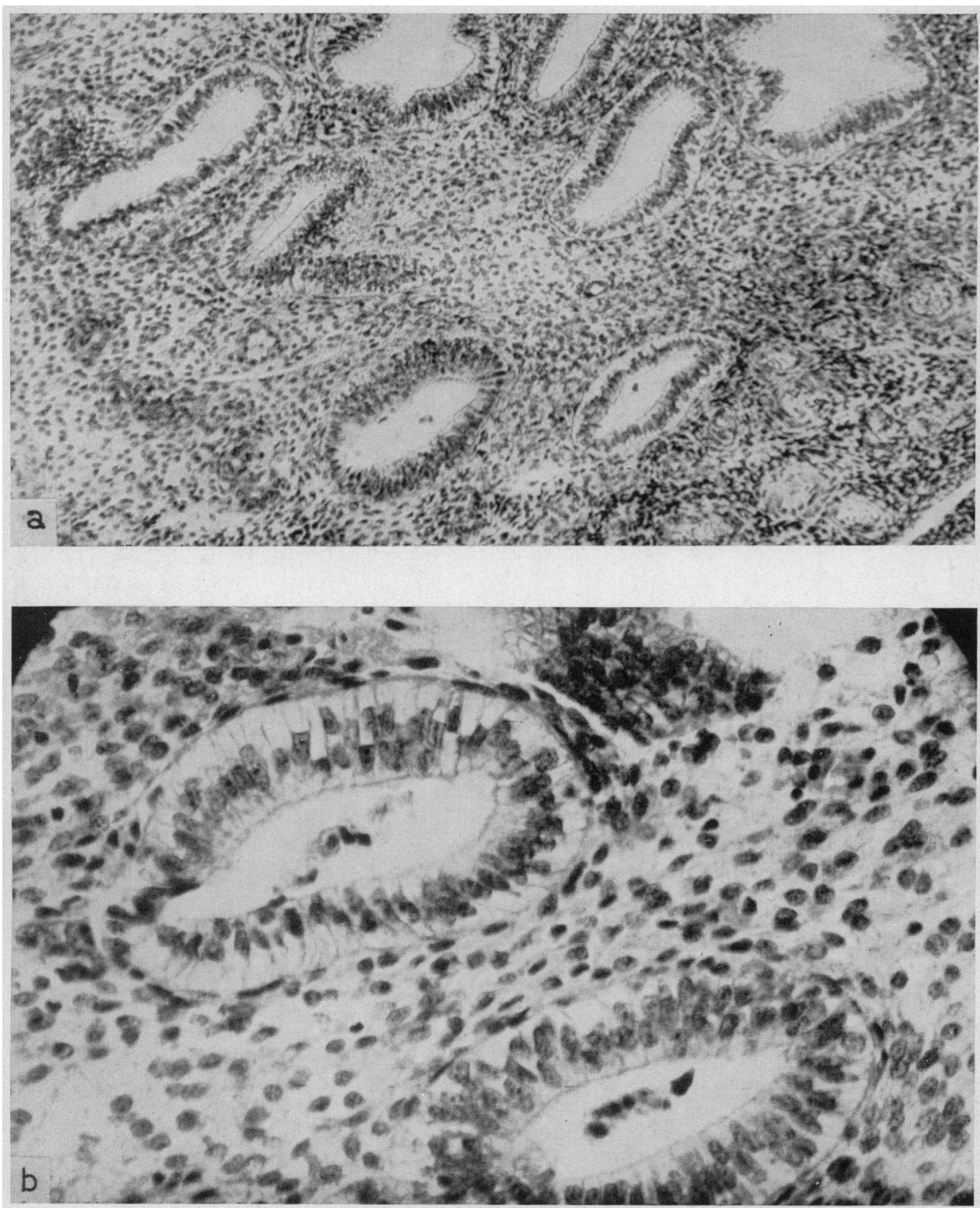

(a) Early secretory endometrium as seen in a biopsy taken on the 26th day of a treatment cycle. $\times 100$.

(b) High power view of the endometrial glands showing a pattern corresponding to that seen on the 17 th day of a normal cycle. $\times 400$.

(Facing p. 120) 
advanced secretory change in the glands and early predecidual change in the stroma. In the sixth case the glands were, however, in the proliferative phase, although the biopsy was performed on Day 26.

\section{DISCUSSION}

The mechanism whereby conception is controlled by combined oestrogen and progesterone therapy has been the subject of much discussion. Venning (1962) finds evidence for the suppression of follicle growth as well as of ovulation, i.e. suppression of both FSH and LH. Holmes \& Mandl (1962) believe that a direct inhibitory action on the ovaries cannot be excluded.

According to Zondek (1941) oestrone activates or depresses the function of the anterior pituitary lobe depending on the amount and duration of hormone administered. Small doses of oestrogen stimulate whereas large doses depress the secretion of FsH. These observations of Zondek have subsequently been elaborated by several studies.

The individual response to oestrogenic compounds varies somewhat and the dose required to inhibit ovulation may range from 0.07 to $0.1 \mathrm{mg}$ of mestranol. In our early experiments the lower doses of $0.07 \mathrm{mg}$ proved to be sufficient in some cases, but inadequate in most women. Mestranol in doses of 0.09 to $0.1 \mathrm{mg}$ was found to be sufficient in all cases. Maqueo, Perez-Vega, Goldzieher, Martinez-Manautou \& Rudel (1963), and Yen (1965) have, respectively, shown that 0.08 and $0.1 \mathrm{mg}$ of mestranol are capable of uniformly inhibiting ovulation. These doses are in accordance with those used in our studies.

Vorys, Ullery \& Stevens (1965) in a study on the effect of sex steroids on gonadotrophins found that no stimulation or suppression of FSH was seen with low doses of mestranol $(0.05 \mathrm{mg} /$ day $)$ but that FSH was effectively suppressed by larger doses $(0.08$ to $0.1 \mathrm{mg})$. Mestranol was also found to be capable of stimulating $\mathbf{L H}$, but longer periods of administration were required to produce this effect.

Since mestranol is an inhibitor of ovulation, the progestational compound given in sequential oral contraception merely serves to regulate the menstrual flow. In our study 17-acetoxy progesterone was seen to satisfy this requirement. Withdrawal bleeding is achieved by giving $100 \mathrm{mg} \mathrm{17-aceto-progesterone,} \mathrm{for}$ 4 to 5 days.

The few endometria available for examination in our study indicate that the sequential hormone therapy is usually followed by secretory changes in the endometrium. On the 25th to 26 th day, the endometrium usually corresponded in appearance to that seen on the 17th to 19th day of a normal cycle. It is of interest, however, that in one patient a proliferative phase endometrium was seen on Day 26. Whereas the great majority of endometrial biopsies examined by Maqueo et al. (1963) after the completion of oestrogen-progesterone sequential theory, showed clear-cut secretory changes, occasional biopsies still showed a proliferative endometrium. These authors have thus drawn attention to the variability of the endometrial response to steroid hormones.

\section{ACKNOWLEDGMENT}

We wish to thank Zori Ltd for supplying the tablets. 


\section{REFERENCES}

Goldzieher, J. W., Becerra, C., Gual, C., Livingston, N. B., Jr., Maqueo, M., Moses, L. E. \& Tietze, G. (1964) New oral contraceptive. Sequential estrogen and progestin. Am. F. Obstet. Gynec. 90, 404.

Goldzieher, J. W., Martinez-Manautou, J., Livingston, N. B., Moses, L. E. \& Rice Wray, E. (1963) The use of sequential estrogen and progestin to inhibit fertility. A preliminary report. West $\mathcal{f}$. Surg. 71, 187.

Holmes, R. L. \& Mandr, A. M. (1962) Oral contraceptives. Lancet, i, 1174.

Maqueo, M., Perez-Vega, E., Goldzieher, J. W., Martinez-Manautou, J. \& Rudei, H. (1963) Comparison of the endometrial activity of 3 synthetic progestins used in fertility control. Am. $\mathcal{J}$. Obstet. Gynec. 85, 427.

Pincus, G., Rock, J. \& Garcia, G. (1958) Effects of certain 19-nor steroids upon reproductive processes. Ann. N.Y. Acad. Sci. 71, 677.

Rock, J., Pincus, G. \& Garcia, G. (1956) Effect of certain 19-nor steroids on the normal human menstrual cycle. Science, N.Y. 124, 891.

Venning, G. R. (1962) Selection and testing of progestational steroids for oral contraception. Proc. $R$. Soc. Med. 55, 863.

Vorys, N., Ullery, J. C. \& Stevens, V. (1965) The effects of sex steroids on gonadotropins. Am. F. Obstet. Gynec. 93, 641.

$\mathrm{Y}_{\mathrm{EN}}$, S. S. C. (1965) Mestranol in ovulation suppression. Fert. Steril. 16, 97.

ZONDEK, B. (1941) Clinical and experimental investigations on the genital functions and their hormonal regulation, p. 28. Williams \& Wilkins, Baltimore. 
The preceding paper concludes the reviews and original papers contributed in

honour of Professor Zondek 